\title{
3D modeling of multimode and single mode fiber
}

\author{
Murizah Kassim ${ }^{1}$, Ahmad Syahir Arif Mohd Zaid ${ }^{2}$, Azlina Idris ${ }^{3}$, Shahrani Shahbudin ${ }^{4}$, \\ Roslina Mohamad $^{5}$, Cik Ku Haroswati Che Ku Yahaya ${ }^{6}$ \\ 1,2,3,4,5 Faculty of Electrical Engineering, Universiti Teknologi MARA, Malaysia. \\ ${ }^{6}$ Universiti Teknologi MARA, Cawangan Selangor, Kampus Dengkil, Malaysia
}

\begin{tabular}{l} 
Article Info \\
\hline Article history: \\
Received Mar 25, 2019 \\
Revised May 27, 2019 \\
Accepted Jun 11, 2019 \\
\hline
\end{tabular}

Keywords:

3D animations

3D modeling

Multimode fiber

Optical fiber

\begin{abstract}
This paper presents a design of 3D modeling of Multimode and Single Mode Fiber using SolidWorks. Fiber technology is essential that presents optical fiber is the fastest optical cable laid by Internet Service Providers in network communication. The current design of both fibers has less detail animation on technical specifications of light propagations and cladding. Thus, characterization difficulties occur between this two fiber optics cables. It also has less promotion in media publications such as 3D model design as guidance to users. This paper presents details on 3D modeling of multimode mode and single mode fiber specifications held in the industry market. A 3D design with SolidWorks and comparison of both fiber characteristics are presented. Based on the 3D designed model, users are analyzed on their perspective and searching information which benefits telecommunication's company. Technical calculations like core-cladding diameter ratio in microns are animated. The propagation of light in $3 \mathrm{D}$ single mode and multimode fiber is simulated using SolidWorks animator that presents it real fiber conditions. Result presents 10 most country searching used of both fiber cables and the difference in users search for both cables. A number of user's search presents $3 \%$ more of multimode than single mode fiber search cases. This research is significant in presenting an animator of single and multimode fiber to users of network infrastructure development especially network developers and Telecommunications Company which can present it lively with animator transitions.
\end{abstract}

Copyright $\odot 2019$ Institute of Advanced Engineering and Science. All rights reserved.

\section{Corresponding Author:}

Murizah Kassim,

Faculty of Electrical Engineering,

Universiti Teknologi MARA,

40450 UiTM Shah Alam, Selangor, Malaysia.

Email: murizah@uitm.edu.my

\section{INTRODUCTION}

The fiber optic cable market size is expanding due to the demand for higher data transmission over long distances and increasing web activity. Another factor driving the market development is the penetration of cell phones and handheld gadgets like tablets and laptops in the consumer market. The growing need for high-speed internet connectivity keeps on driving the fiber optic cable market. The high expenses and complex installation process act as major threats for the growth of the market for fiber optics cable compared to traditional copper cables [1]. On the basis of application, telecom and broadband segment is expected to dominate the market during the forecast period for 2018 to 2026 [2]. Currently, the growth of fiber optic cables in telecom and broadband segment is recognized by its numerous applications in telecom and broadband companies to transmit telephone signals, cable television signals and internet communication where more research on fibre enhancement is done [3, 4].

3D modeling of single mode and multimode fiber specification held in the industry market shows it indifference categories. A 3D scheme has expanded the design possibilities of SERS nanostructures on the 
facets of optical fibers enormously [5]. Two common telecommunications company in Malaysia used fiber in providing users the internet service is Telekom Malaysia TM and Maxis. Both companies probably used the same or different type of fiber for their internet service. The concept of propagation of light when using a different type of fiber showed in 3D Model of light propagation of single and multimode fiber is important [6]. It makes easier for users to understand and differentiate between the two type of fiber and how the propagation of light through the animations compares to the text document. Learning through images and online is important where it supports towards education 5.0. Some design and the developed system is successfully done by using an identified mobile system which easily classified the chapter's information from identified captured logo which helps the learning activity [7]. Few ways are identified to design 3D modeling of light propagation through fiber such as using SolidWorks software. SolidWorks is a computer-aided engineering computer program and a solid modeling computer-aided design that allows a user to design components part into 2D or 3D dimension [8]. It has great modeling capabilities including part of modeling, assemblies, and drawings such as the creation of families with configuration tools and special motion in engineering disciplines [9]. Review of modern three-dimensional integration technologies and analysis of prospects of their use for high power micro-assemblies have been done shows a better 3D concept in technologies [10]. Other famous 3D modeling software is Unity3D. The software used to develop the interactive video game. Unity3D needs JavaScript or C\# to be operated where it specialized for the game engine [11]. Animated model can be sketched with the 2D model first before proceeded to 3D modeling [12]. Many 3D modeling has recently been designed to realize the knowledge and understanding like in video based action recognition, Android-Base 3D Visualization [13], 3D Linear techniques[14], 3D-OFDM channel estimation [15], generated 3D cable models [16], 3D Fibre modeling signals [17], 3D printing for a fiber brag grating [18] and many more that shows theimportant of 3D modeling in new technologies.

This research presents a 3D modeling for multimode and single fiber using solid works applications. Some technical design on modeling concept and technical calculations on core-cladding diameter ratio in microns are animated. The propagation of light in 3D single mode and multimode fiber is simulated. The result presents some trends in cable optic market by region and type of optic cables which is significant in qualitative and quantitative research of the market, as integrates the insights into the rational scenario and favored development methods adopted by the key challenges for the growth of fiber optics.

\section{OPTICAL FIBERS CHARACTERISTIC}

An optical fiber is widely used in telecommunications because of its advantage compare when using copper as data transmission. Besides it is used in transmission, optical fiber also widely used in sensor and power transmission. Optical fibers are largely used in communications which transmit some data transmission over great distances and at greater bandwidths than other communication methods [19]. Fiber Optics is sending signals down throughout of plastic or fiberglass. The ray light is directed down the core center of the fiber. Most of the optical fibers are made of glass because silica glass properties that are scattering losses and extremely low absorption [20]. A capacity of fiber-optic communication systems is estimated to be limited by a nonlinearity of fiber which discloses that a capacity of $\sim 5 \mathrm{bits} / \mathrm{s} / \mathrm{Hz}$ in a single polarization for transmission greater than $2000 \mathrm{~km}$ can be done using advanced technologies [21]. There are numerous single-mode fiber components consist of some form of optics, such as mirrors or lenses, for gathering light from a laser or source fiber and focused it on a reception fiber [22]. Figure 1 shows single mode fiber is at $9 / 125$ in construction that allows single of light to propagate through it since it has a small diameter core. Figure 2 shows Multimode fiber has two dimensions which are at 50/125 and 62.5/125 in construction. Multimode fibers have larger cores $(62.5 \mu \mathrm{m}$ or $50 \mu \mathrm{m})$ compare to single mode fiber that conducts several modes instantaneously.
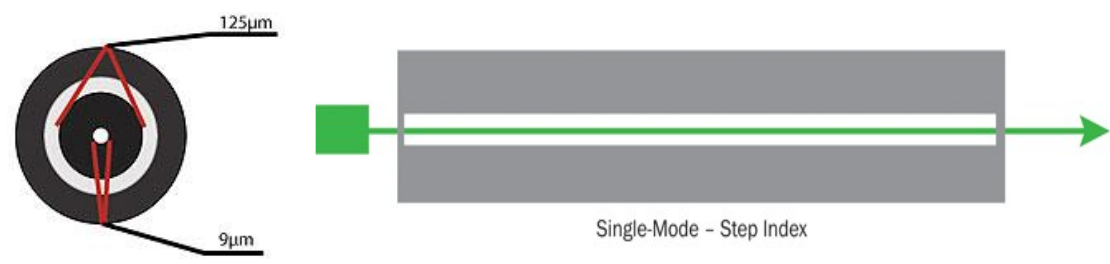

Figure 1. Single mode and Light propagation construction 

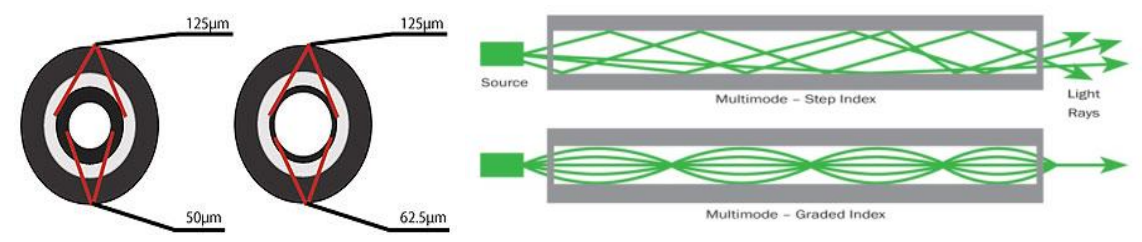

Figure 2. Multimode fiber and light propagation construction

Thus, more light reflections formed when the light goes through the core increases, forming the ability for additional data to pass through at a certain time. Since the multimode fiber is dependable and has great capacity, multi-mode optic fiber commonly is used for pillar applications in certain buildings [23]. Normally, this application is used for small distance, data of audio and video applications in LANs. The research identified that bandwidth and data rate increased but the maximum distance is covered and reduced for multimode fiber [24]. Beside, multimode fiber also is used as a high-resolution, lossless spectrometer [25].

\section{METHODOLOGY}

The methodology for this research comprised of designed 3D animators and analyzed search users on fiber materials. Figure 3 shows the flowchart of a full design project and Figure 4 shows a flowchart of modeling cables in the 3D design model. First, the optical fiber animator of light propagation is designed by drawing the $2 \mathrm{D}$ model of an optical fiber with corrects dimensional of the fiber. Sketching 3 parts of the compulsory component which is fiber optic, light source, and ray light are drawn. Then, it is extruded the entire component to create a solid feature 3D feature of the components. All parts are assembled for the 3D model and rearrange it at a suitable place. Lastly, the creation of light propagation is derived, and animation of the propagation is designed. First, a 2D animation model is created on the fiber part by selecting the front plane and sketches it on the plane with the details specification of the fiber. Then the 3D model of the design is continued from the 2D modeling. After sketching the 2D model, extrude the base feature to create the solid build of the design.

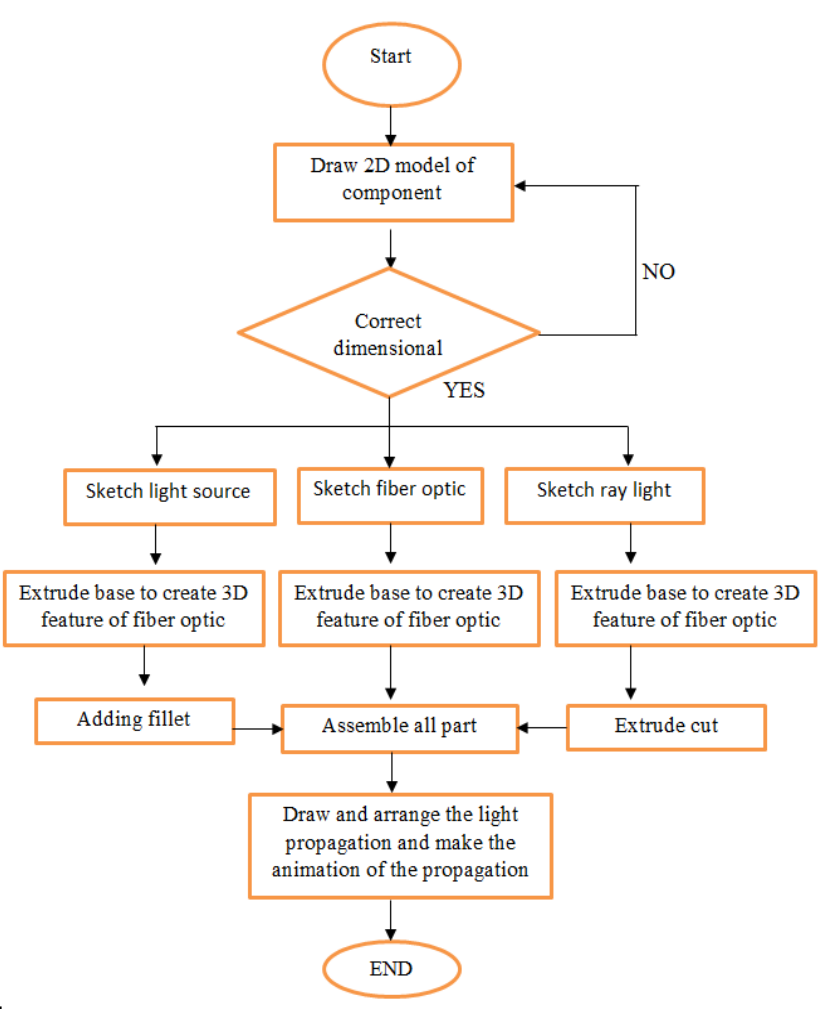

Figure 3. Flowchart of design model

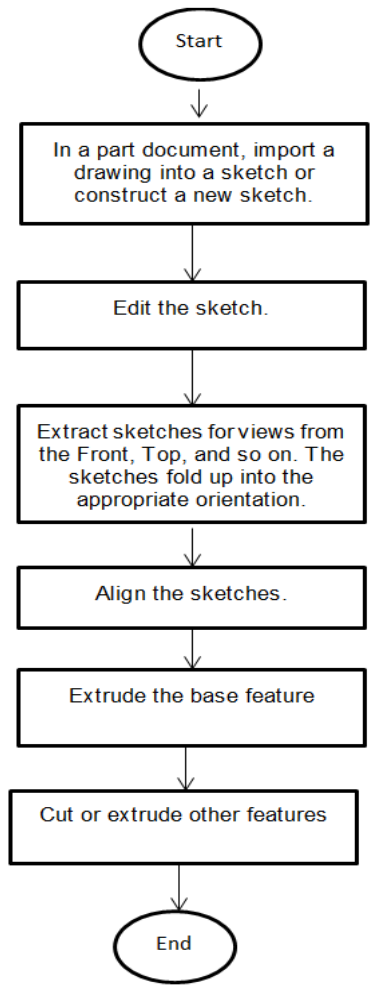

Figure 4. Flowchart of modeling object in 3D 


\section{RESULT AND DISCUSSION}

Results obtained the propagation of light designed happen in single mode and multimode fiber in 3D animation was successfully developed.

\subsection{D Modeling of Multimode Optical Fiber}

Figure 5 shows the animator and details specification of multimode fiber. First sketch circle in 2D on a front plane with the detail specification of multimode fiber for the core part that is the core to cladding diameter ratio is $50 \mathrm{um}$ (microns) to $125 \mathrm{um}$ (microns). Then extrude the sketch to create the solid feature of fiber with 500um long. After that, sketch the light source of the fiber. The step to sketch the light source is almost the same as above. First, sketch the circle at the front plane with a diameter of 40um and extrude the base to create the solid feature of the light source with 60um long by setting it at depth. Next is sketch another 2 circles on the front plane of the solid feature with a diameter of inner of $12 \mathrm{um}, 20 \mathrm{um}$ for outer circle and the depth of $5 \mathrm{um}$. Next, create the round internal or external face along the edges in solid or face feature of the light source. Choose the face feature, click the fillet and choose the Constant Size Fillet. Under Fillet Parameters, set the radius to $0.5 \mathrm{um}$. Set it to all edges of the solid face feature.
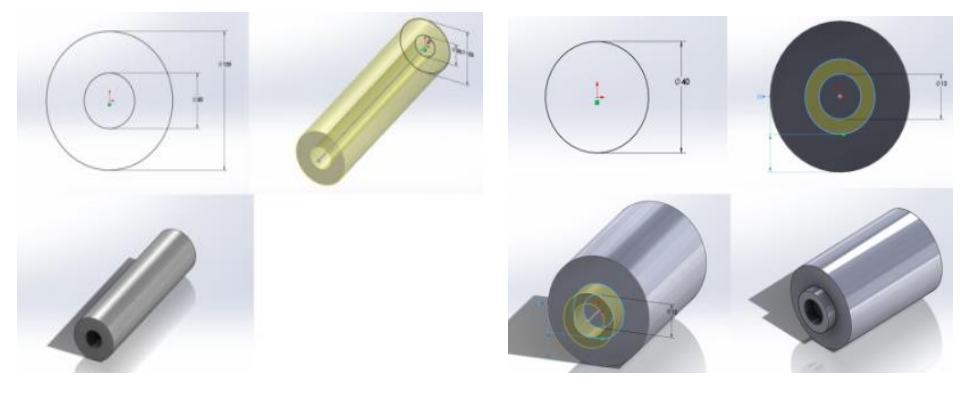

Figure 5. 3D modeling for Light source and fillet feature of a light source

Figure 6 shows the creation of ray light. The first step is almost the same as the previous component. Sketch the circle at the front plane with a diameter of 10um and extrude the base to get the solid feature of the ray light. The length of the ray light can be adjusted when executing the base extrude by setting the depth to 200um. After that, to make the ray is proportional to the inner fiber when assembling them, the tip end of the ray light must be cut. First, select the right plane of the features and sketch the line about 45 degrees that need to be cut. After sketching the line, click the Extruded Cut and select Through All. Figure 7 shows all components being assembled in one part. After that, arrange all part as shown in the figure above. To create the ray light reflection in optical fiber, create another ray light and arrange it in a sequence of the 45 degrees line that has been sketched on the right plane. To make it easier when arranging the ray light, hide the optical fiber. Next step, to create the reflection pattern, create the mirror components of the ray light. First, create a new front plane at the last ray light and select the ray that needs to be mirror before making confirmation. Next, create another front plane and select the ray light that needs to be duplicated. Repeat the procedure until the ray light fills at the end of the fiber. Figure 5 below shows the complete optical fiber with light propagation.
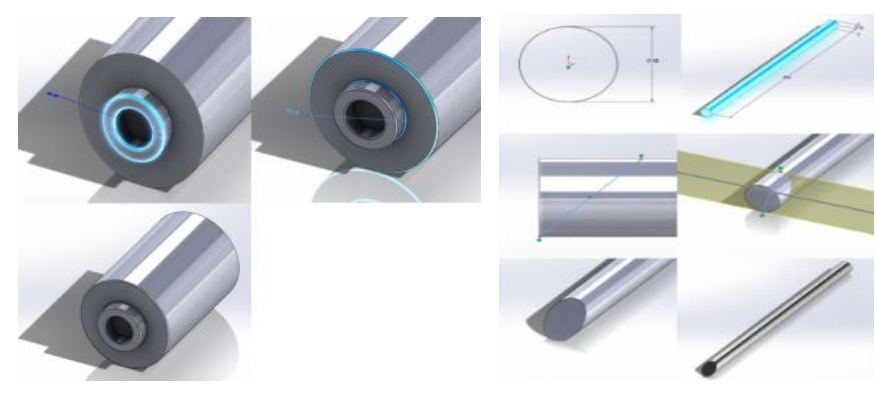

Figure 6. 3D Modeling for Multimode fiber and ray light 


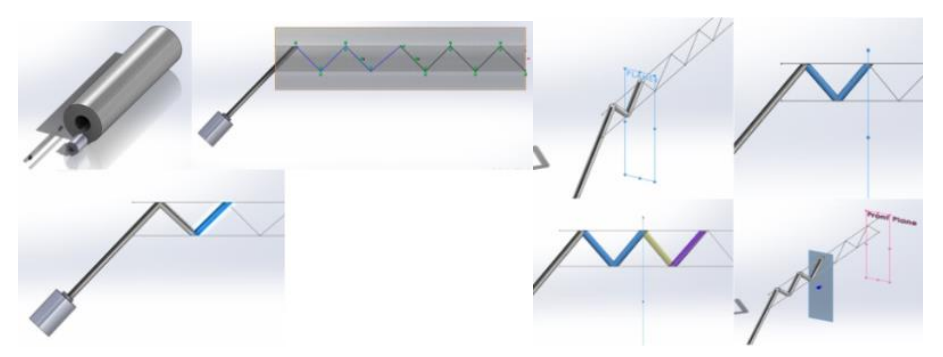

Figure 7. 3D Modeling on assembling components and reflection pattern

\subsection{D Modeling of Optical Light Propagation}

Figure 8 shows the completed light propagation in the inner of multimode optical fiber before going through animations. The animation of the ray light propagation is designed by moving to Motion Study part. The first step, all the ray light must be hidden first. The time bar to control the timing of the moving component. Next step shows all the rays one by one by following the sequence of ray's movement. The time for one ray show one after another is exactly 2 seconds and a total of all rays appear is 10 second. The time is fixed to 5 times faster to show faster appearance and movement of the rays. After showing all the rays and fix the time, calculate button to show the animation of light propagation.

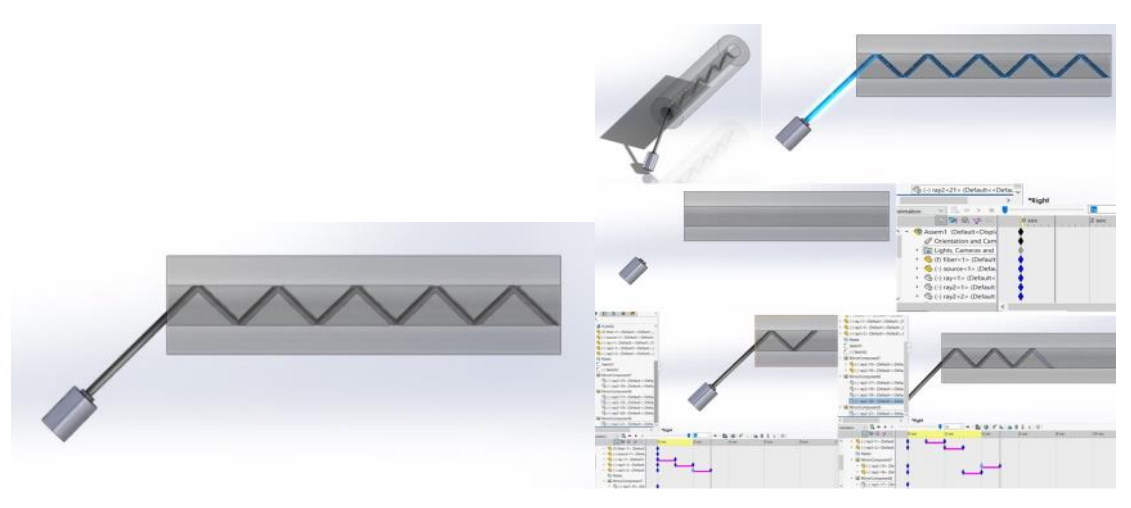

Figure 8. Completed 3D model on the optical fiber with light propagation

\subsection{Developing the Single Mode Optical Fiber}

Light propagation in single-mode optical fiber drawing designed used all steps as developed the multimode optical fiber, light source and the ray light propagation except for the movement of light as it moves in straightway. Figure 9 shows the measurement for single mode fiber. The detail specifications for the construction of single-mode fiber are the core to cladding diameter ratio of about 9 microns to 125 microns. The length of the fiber is 350um while the diameter and length of the ray light are 5um and 35um respectively. All parts are assembled and arranged then all rays in the fiber are hidden to model in 3D. Later, it is shown one by one along with adjusted time and lastly, a calculation is pressed to show in a 3D model.

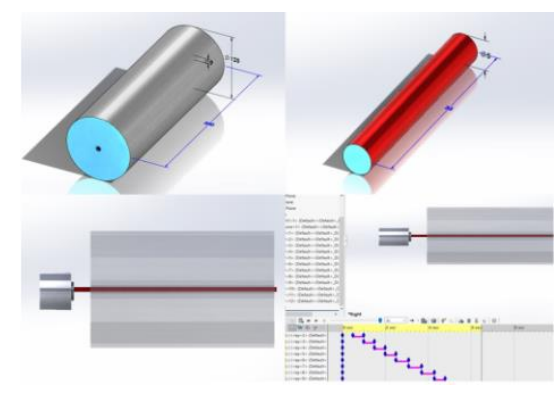

Figure 9. Step to develop single mode optical fiber and the animation of light propagation 


\subsection{Data on Users Search Demand on Fibers}

Figure 10 shows the data collected on interest over time for single mode optical fiber. Users searching single mode optical fiber around the worlds for the past year are shown on the graph and the table above. Figure 11 shows the most searching is China, the biggest country in the world. People from China shown the most interest in this single mode optical fiber followed by Qatar in second place and Oman at the third place for the year 2017 until the recent time in the year 2018.

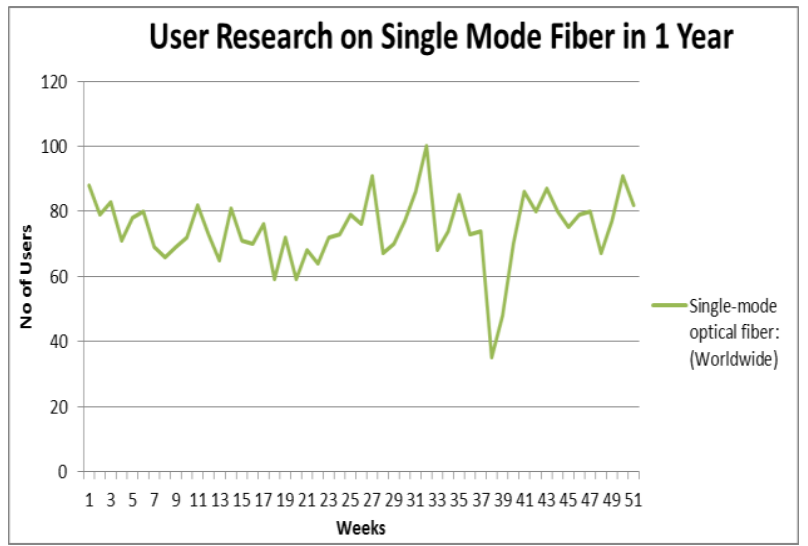

Figure 10. Interest over time for single mode fiber

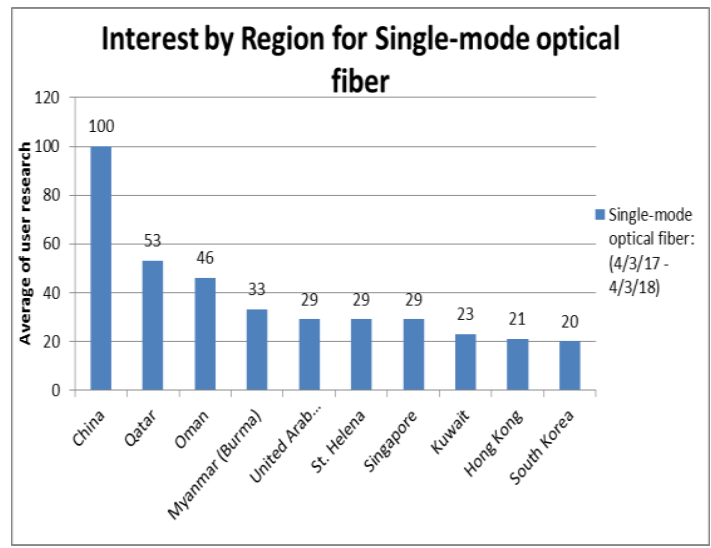

Figure 11. Interest by region

Figure 12 shows the interest over time for multi-mode optical fiber. Data shows people searching multi-mode optical fiber around the worlds in one year. Figure 13 identified that China is still the country need and it is the biggest interest for both single mode and multi-mode fiber. The second region that shows interest over multi-mode fiber from the collected data is Singapore followed by the United Arab Emirates at third place.

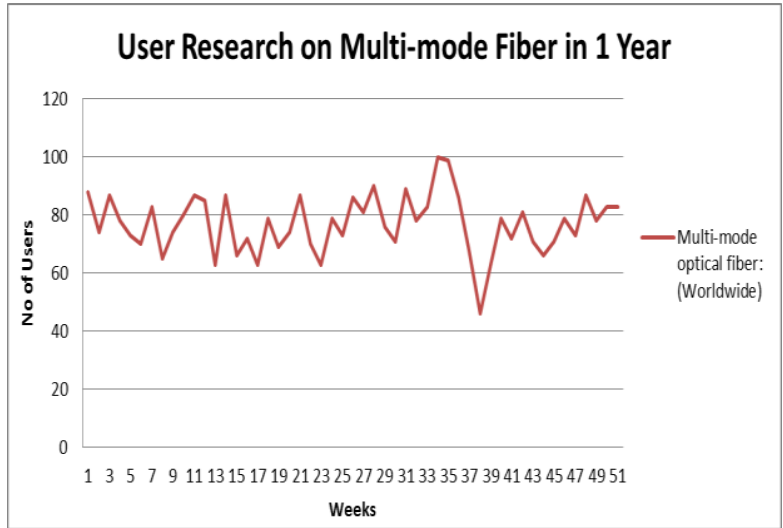

Figure 12. Interest over time for multi-mode fiber

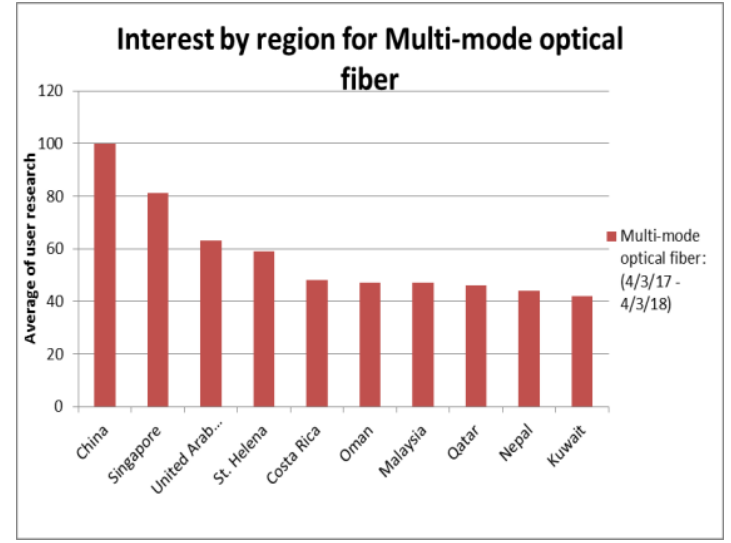

Figure 13. Interest by region

Figure 14 shows the difference between multimode compared to Single mode optical Fiber search by the user. The average shows that users tend searching more on multimode fiber compare to single mode fiber. The average number of users that search for multimode fiber is 77 , which is slightest different only from user search on single mode fiber that is 74.5 as shown in Figure 15. People show interest more on multimode fiber probably because it can transfer more data compare single mode and others advantage that single mode fiber doesn't have. 


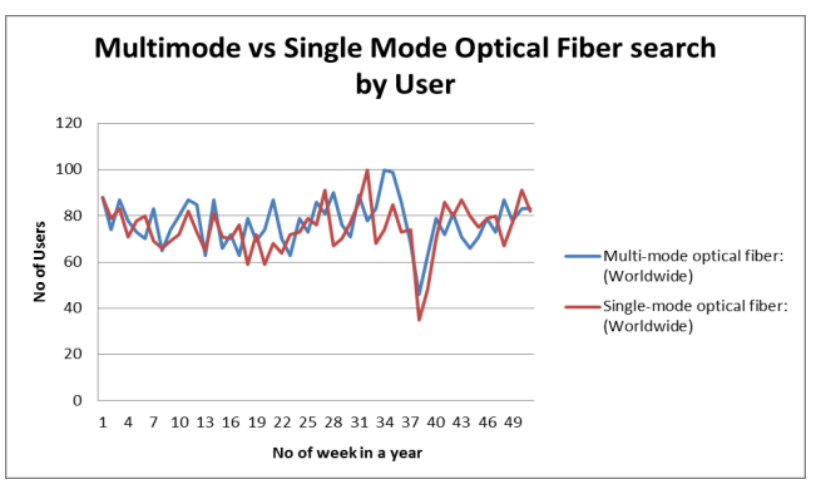

Figure 14. Fiber search by User

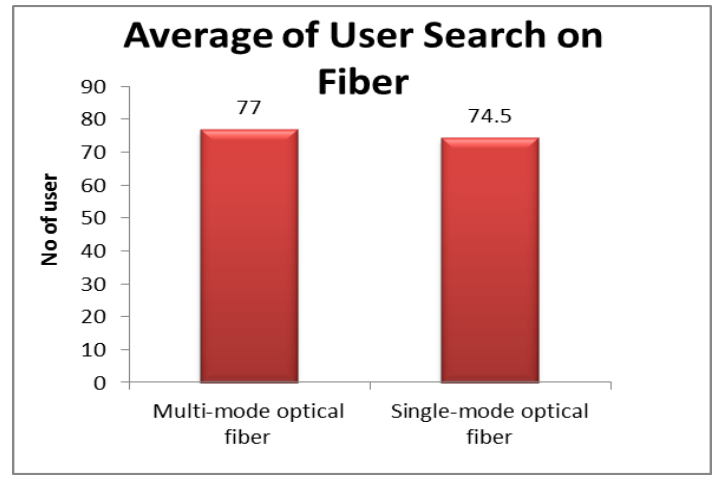

Figure 15. Average of User Search on Fiber

\section{CONCLUSION}

As a conclusion, this project has been achieved to design single mode and multimode fiber with detail specifications animations in 3D using SolidWorks animator software. Both fiber optics cables held in the industry market are designed in detail specification in 3D animations. Users need information on the fiber cable specifications also are analyzed based on users search perspective using Google search data that trending analyzed for one year started in 2017. Both 3D designs are to be published the 3D model simulator as multimedia publisher such on a website or courses need by Telecommunication Company. This research is significant in educating users to learn on fiber optics specifications that were designed in 3D model design concept. It also benefits to users in network communications and telecommunication and the telecommunication company can make use of this 3D model as media publisher through their website in promoting consumers and services of marketing network equipment and fiber cables.

\section{ACKNOWLEDGMENT}

The author would like to thank Universiti Teknologi MARA for the supported grant LESTARI $0017 / 2016$ in publishing this paper.

\section{REFERENCES}

[1] J. Ratkoceri, B. Batagelj, and I. Humar, "Upgrade of a hybrid fiber/coax broadband access based on a technoeconomic analysis and prediction of the traffic growth," Elektrotehniski Vestnik-Electrochemical Review, vol. 85, pp. 95-102, 2018.

[2] A. M. Insights. (2018, Fiber Optic Cable Market 2018-2026. Available: https://www.absolutemarketsinsights.com/reports/Fiber-Optic-Cable-Market-2018-2026-20

[3] C. Lee and S. M. Chan-Olmsted, "Competitive advantage of broadband Internet: a comparative study between South Korea and the United States," Telecommunications Policy, vol. 28, pp. 649-677, 2004.

[4] H. Haris, A. R. Muhammad, N. Saidin, M. S. Z. Abidin, H. Arof, M. C. Paul, and S. W. Harun, "Dual-wavelength thulium ytterbium Co-doped fiber laser," Indonesian Journal of Electrical Engineering and Computer Science, vol. 8, pp. 457-46, 2017.

[5] Z. Xie, S. Feng, P. Wang, L. Zhang, X. Ren, L. Cui, T. Zhai, J. Chen, Y. Wang, and X. Wang, "Demonstration of a 3D Radar-Like SERS Sensor Micro-and Nanofabricated on an Optical Fiber," Advanced Optical Materials, vol. 3, pp. 1232-1239, 2015.

[6] N. Yusof, H. Razak, H. Arof, and S. W. Harun, "Multimode interference in single mode-multimode-single mode fiber structure for steel beam compressive strain measurement," Microwave and Optical Technology Letters, vol. 60, pp. 1971-1975, 2018.

[7] M. Kassim, A. E. K. Suandi, A. Idris, and W. N. W. Muhamad, "MOBILE LEARNING MODULE SYSTEM WITH LOGO CHARACTERIZATION," International E-Journal of Advances in Education, vol. 3, pp. 458-468, 2017.

[8] K.-H. Chang, Motion Simulation and Mechanism Design with SOLIDWORKS Motion 2018: SDC publications, 2018.

[9] O. M. Aleksieiev, M. M. Korotun, and D. V. Trebukhov, "The Use of Animation as a Means to Increase Motivation among Students of Engineering Disciplines," Information Technologies and Learning Tools, vol. 65, pp. 76-90, 2018.

[10] A. Sukhanov, A. Artemova, and R. Litvinenko, "Review of Modern Three-Dimensional Integration Technologies and Analysis of Prospects of Their use for High Power Micro-Assemblies," Indonesian Journal of Electrical Engineering and Computer Science, vol. 9, pp. 198-203, 2018. 
[11] M. Kassim and M. N. H. M. Said, "Data analytics on interactive indoor cycling exercises with virtual reality video games," in 2018 4th International Conference on Control, Automation and Robotics (ICCAR), 2018, pp. 321-326.

[12] B. Sun, G. Qin, and Y. Fang, "Research of standard parts library construction for SolidWorks by Visual Basic," in 2011 International Conference on Electronic and Mechanical Engineering and Information Technology (EMEIT), 2011, pp. 2651-2654.

[13] L. Karlitasari and A. P. P. Ismanto, "Android-Base 3D Visualization of Indonesia Medicinal Plants," TELKOMNIKA Indonesian Journal of Electrical Engineering and Computer Sciences, vol. 5, pp. 229-232, 2017.

[14] A. S. Yaro, A. Z. Sha'ameri, and N. Kamel, "Position Estimation Comparison of a 3-D Linear Lateration Algorithm with a Reference Selection Technique," Indonesian Journal of Electrical Engineering and Computer Science, vol. 10, pp. 207-213, 2018.

[15] D. N. Bhange and C. G. Dethe, "Performance of Pilot-Aided 3D-OFDM Channel Estimation using Different Antenna Configurations," Indonesian Journal of Electrical Engineering and Computer Science, vol. 8, pp. 77-84, 2017.

[16] T. Goto, M. Waki, and K. Katayama, "Highly Accurate and Efficient Maintenance Technology for Optical Cables and Utility Poles," in 2018 Optical Fiber Communications Conference and Exposition (OFC), 2018, pp. 1-3.

[17] R. J. Mellors, C. Yu, C. Mart, C. Sherman, P. Pax, K. Fisher, G. Allen, M. Messerly, J. Morris, and F. J. Ryerson, "Understanding distributed fiber optic sensing response for modeling of signals," in SEG Technical Program Expanded Abstracts 2018, ed: Society of Exploration Geophysicists, 2018, pp. 4679-4682.

[18] Z. A. Abro, Y. Zhang, and C. Hong, "A Fiber Bragg Grating-Based Inclinometer Fabricated Using 3-D Printing Method for Slope Monitoring," Geotechnical Testing Journal, vol. 43, 2019.

[19] S. P. Mohanalakshmi, S. S. Ramesh, S. K. Radhakrishnan, S. G. R. Kannan, and S. V. Sathyanarayanan, "Bit error rate measurements of fiber optic network through ethernet analysers," in 2017 International Conference on Information Communication and Embedded Systems (ICICES), 2017, pp. 1-5.

[20] K. Thyagarajan and A. Ghatak, Fiber optic essentials vol. 10: John Wiley \& Sons, 2007.

[21] R.-J. Essiambre, G. Foschini, P. Winzer, and G. Kramer, "Capacity limits of fiber-optic communication systems," in Optical Fiber Communication Conference, 2009, p. OThL1.

[22] F. Zhang, Y. Zheng, S. Lu, D. Luo, and J.-a. Duan, "Coupling efficiency between ball lens capped laser diode chip and single mode fiber," Optik-International Journal for Light and Electron Optics, vol. 157, pp. 497-502, 2018.

[23] H. Buelow, H. Al-Hashimi, B. T. Abebe, and B. Schmauss, "Capacity and outage of multimode fiber with statistical bends," in Optical Fiber Communication Conference, 2012, p. OW3D. 2.

[24] S. Kanprachar, "Effects of bandpass bandwidth in bit-rate and distance of subcarrier multiplexing on multimode fiber," in 2012 11th International Conference on Optical Communications and Networks (ICOCN), 2012, pp. 1-4.

[25] B. Redding, S. Popoff, and H. Cao, "Using a multimode fiber as a high-resolution, low-loss spectrometer," in CLEO: Science and Innovations, 2013, p. CTu3I. 4.

\section{BIOGRAPHIES OF AUTHORS}

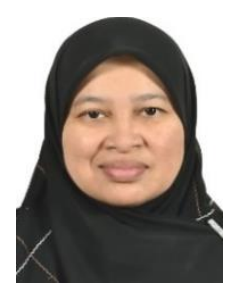

Murizah Kassim is currently working as senior lecturer at Faculty of Electrical Engineering, Universiti Teknologi MARA, Shah Alam, Selangor. She received her PhD in Electronic, Electrical and System Engineering in 2016 from the Faculty of Built Environment and Engineering, Universiti Kebangsaan Malaysia (UKM), Malaysia. She has published many papers related to computer network, IoT, web and mobile development applications research. She experienced about 19 years in technical team at the Centre for Integrated Information System, UiTM. She is also the member of Enabling Internet of Things Technologies (ElIoTT) research group UiTM. She joined the academic since January 2009 and currently member of IEEE, IET, IAENG and IACSIT organization.

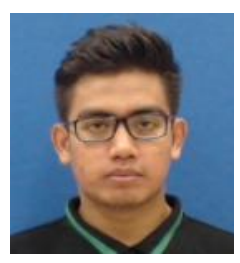

Ahmad Syahir Arif Mohd Zaid, obtained a Bachelor of Engineering (Hons) Electrical Engineering in 2018 from Universiti Teknologi MARA, UiTM Shah Alam, Selangor, Malaysia. During his studies, he is active in club and societies to improve his communication and interpersonal skills. He is ambitious who is currently looking to broaden his career path. He is interested in power and electrical engineering.

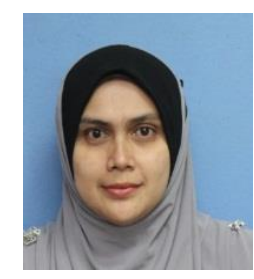

Azlina Idris is a Senior Lecturer at the Universiti Teknologi MARA (UiTM), Selangor, Malaysia. She obtained her PhD in wireless communication from University Malaya (UM), Malaysia. She has received the Master of Engineering in Electrical from Universiti Teknologi Malaysia (UTM). Previously, she obtained her first degree from Leeds Metropolitan University, United Kingdom with Honours, in Applied Computer. She is a member of Wireless Communication Technology (WiCOT) Research Interest Group (RIG) and her research interests include OFDM/OFDMA transmission, single and multiuser precoding, modulation, MIMO transmission techniques and receivers, channel coding, interference management and mitigation, and channel modeling (channel estimation). 

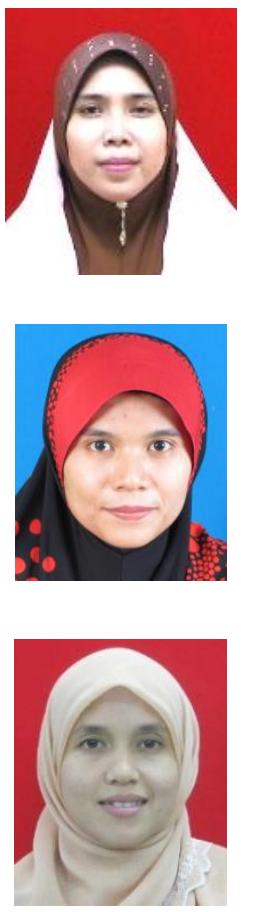

Shahrani Shahbudin received B.Eng.(Hons) degree from the University of Malaya, Kuala Lumpur in 1999. Master and Phd in 2004 and 2014 from Universiti Kebangsaan Malaysia respectively. She is currently working as a senior lecturer at the Centre for Computer Engineering Studies, Faculty of Electrical Engineering, University Teknologi MARA (UiTM) Shah Alam and member of MBOT, IEEE, IEM and BEM organization. Her main research interests include machine learning, deep learning, intelligent system, pattern classification and IoT for classification and visualization.

R. Mohammad obtained the B. Eng. degree in Electrical Engineering and M. Eng. Science degree from Universiti Malaya, Kuala Lumpur in 2003 and 2008 respectively. She received the $\mathrm{PhD}$. degree in Aerospace Engineering from Universiti Putra Malaysia, in 2016. From 2006 until now, she is with Faculty of Electrical Engineering, Universiti Teknologi MARA, as a senior lecturer. She has been appointed as a Head of Computer Engineering Studies at the same institution since 2018. Her research interests are in computing algorithm and digital signal processing for deep space communication, channel coding, theory of computation, and wireless communication.

Cik $\mathrm{Ku}$ Haroswati Che $\mathrm{Ku}$ Yahaya is currently working as a lecturer and cisco academy instructor, Malaysia at Faculty of Electrical Engineering, Universiti Teknologi MARA, Shah Alam, Selangor. She received her Bachelor Degree(hons) in Informatiom System from UKM in 1998 and MSc degree from UiTM in 2006. Since 2009 joined UiTM she published a numbers of indexed conference papers and international journal. Her research interest includes the data communication, wireless technology, mobile, IOT and Big Data 